\title{
INTERACTIVE DATA PREPROCESSOR PROGRAM FOR MICHIGAN SAP (MSAP) $\dagger$
}

\author{
MOVSES J. KALDIIAN \\ Departments of Civil Engineering and Naval Architecture and Marine Engineering, College of Engineering, \\ The University of Michigan, Ann Arbor, MI 48109, U.S.A.
}

(Received 30 November 1975)

\begin{abstract}
To extend the usefulness of the Michigan Structural Analysis Program (MSAP), a data preprocessing program called PREMSAP has been developed. It is a format free interactive program to prepare the input data for MSAP, and can be run from any terminal on a time sharing computer system.

PREMSAP provides the student/engineer an easy and efficient way of communicating the mathematical model of his simple structure to the computer and obtaining his results in a matter of minutes without the tedious work of learning and preparing formatted statements for MSAP and MSAPLOT its graphic display partner. It can be used equally well with SOLID SAP or SAP IV.

Use of PREMSAP in teaching structural subjects proved successful.
\end{abstract}

\section{INTRODUCTION}

This paper is prepared to describe the interactive input data preprocessor program PREMSAP to the users of Michigan Structural Analysis Program (MSAP) and MSAPLOT[1].

MSAP which is a modified version of SOLID SAP [2], is a linear general purpose two or three dimensional finite element program. Its input format is rather involved for small ordinary structures, especially so, since there are many options available. Many structural problems are quite simple so far as MSAP application is concerned, but unfamiliarity and complicated description and input format often discourage the unitiated from using it.

The purpose of PREMSAP therefore is to provide the student/engineer a real easy and an efficient way of communicating his mathematical problem to the computer, and to obtain his results by avoiding unnecessary and time consuming mistakes, i.e. to bypass the tedious work of preparing formatted input data statements for MSAP and MSAPLOT.

PREMSAP is a format free interactive program and can be run from any terminal on a time sharing computer system. It is written in FORTRAN IV and is operational on IBM $370 / 168$ and Amdahl $470 \mathrm{~V} / 6$ at the University of Michigan.

Input data formats of MSAP and MSAPLOT are identical with those of SOLID SAP [2] and SAP IV [3] (in static mode for cartesian coordinates with element type 9 excluded). Thus PREMSAP may be used equally well with SOLID SAP or SAP IV.

\section{INPUT/OUTPUT}

PREMSAP is an interactive mode input program developed to lead the user each step of the way to communicate all the details of his problem to the computer.

After the user has defined his problem, with proper sketches and dimensions, from a terminal he calls on PREMSAP. The computer responds by printing a statement requesting some specific piece of information

tPresented at the Second National Symposium on Computerized Structural Analysis and Design at the School of Engineering and Applied Science, George Washington University, Washington, D.C., 29-31 March 1976. from the user regarding his problem. The user answers back by typing the required information and then returns the carriage. When more than one item is requested per line they must be separated by commas. Either integer of floating point number can be used throughout.

The process of requesting information by the computer, and the user's response to it continues till the last bit of information necessary to complete the input data for MSAP is accomplished.

All the information received above is stored internally by the computer on two separate files with different formats. The first file is called "CDATA". Its main purpose is to be able to detect errors. The second file which can be either temporary or permanent is to be named by the user as he chooses. It contains the information supplied by "-CDATA", edited and stored according to MSAP input format ready to be run in MSAP or MSAPLOT.

It is of course recommended though not essential for simple problems, to read the MSAP (SOLID SAP or SAP IV) manual and get acquainted with finite element techniques prior to running PREMSAP on the terminal.

\section{PROGRAM DESCRIPTION}

MSAP contains the following eight element types (see SOLID SAP [2] or SAP IV [3] manual for details).

(1) Three dimensional truss

(2) Three dimensional beam

(3) Plane stress and plane strain

(4) Plane stress, plane strain and axisymmetric

(5) Three dimensional solid

(6) Plate and shell

(7) Boundary

(8) Thick shell element.

The above element types are grouped by PREMSAP into four categories namely,

\section{Two dimensional problems}

(1) truss, plane stress, plane strain, axisymmetric and boundary elements

(2) beam, plate and shell and boundary elements

Three dimensional problems

(3) truss, three dimensional solid, thick shell and boundary elements 
(4) beam, plate and shell and boundary elements.

The first information to be supplied is the title of the problem on one line. This is followed by the number of joints (nodal points), the number of element types, and the number of load cases. Then through two yes or no type questions PREMSAP identifies the category of the problem being studied. These are

... IS THE PROBLEM 2-DIMENSIONAL?

... ENTER Y FOR YES OR N FOR NO

and

\section{... ARE THERE BEAM, THIN SHELL OR \\ ... PLATE ELEMENTS INVOLVED ... IN THE PROBLEM? (ENTER Y OR N)}

After these questions are answered, the program prompts the user for specific information according to the category of elements being used. They include

\section{(1) Nodal point data}

The boundary condition codes ( 0 for free, 1 for constrained)

The coordinates

\section{(2) Element data}

Element type number

Number of elements

Number of different materials

(a) Material properties

(b) Geometric properties

Element Nodal Points.

\section{(3) Load data}

Number of joints with concentrated loads and moments.

As mentioned earlier, all the data the user enters in the computer is stored in the temporary file "-CDATA" created by the program. The user may ask for the listing of " CDATA" and check his figures. If there are mistakes file "-CDATA" must be edited and revised.

If no listing is desired or after the corrections are made, the program reads the data from "-CDATA" into a second file ("FILE2") which is to be named by the user himself. "FILE2" is the required input for MSAP.

The user is now ready to obtain his results by typing

$$
\text { \$RUN MSAP 5=FILE2 (for Structural Analysis) }
$$

or

\section{\$RUN MSAPLOT $5=$ FILE2 (for Graphic Display).}

For further details the reader is referred to the illustrative examples in the Appendix.

\section{SUMMARY AND CONCLUSIONS}

The preceeding interactive program PREMSAP is very easy to use. It is intended to facilitate and thereby encourage beginners (notably engineering students) to use MSAP (SOLID SAP, SAP IV) and MSAPLOT in small size ordinary type structural problems normally encountered in classroom assignments.

PREMSAP is format free and requires a minimal knowledge of the computer and finite element methods.

Use of MSAP (SOLID SAP or SAP IV), and MSAPLOT manuals are highly recommended for an understanding of the mechanics behind the PREMSAP process.

In an indirect fashion PREMSAP may also be used in large and complicated structural problems. Since the overall skeleton of the MSAP input data format is the same for small, as well as large and complicated problems, the user can first obtain his input data ("FILE2") from PREMSAP for a small simplified model of his problem. Then he edits by adding and modifying it directly as required by his large and involved problem, thereby reducing heavy dependence on formatted statements and on general purpose program complications.

Use of PREMSAP in teaching structural subjects proved to be very valuable and successful here at Michigan. Its use is highly recommended.

Acknowledgements-The assistance of Kiang Ning Huang in preparing this program and the financial support in part of the National Science Foundation. Grant NSF-67 2898 is gratefully acknowledged.

\section{REFERENCES}

1. M. J. Kaldiin and K. N. Huang, User's guide to MSAPLOTA 3-D interactive graphic display program for the input and output data of Michigan structural program MSAP. No. 172 Dept. of Naval Arch. and Marine Engng., Univ. of Mich., Ann Arbor. Mich. (June 1975).

2. E. L. Wilson, SOLID SAP-A static analysis program for 3-D solid structures. UC-SESM 71-19 Dept. of Civil Engng., Univ. of Calif., Berkeley (Dec. 1972).

3. K. J. Bathe, E. L. Wilson and F. E. Peterson, SAP IV-A structural analysis program for static and dynamic response of linear systems. EERC 73-11 Earthquake Engng. Research Center, College of Engng., Univ. of Calif., Berkeley (June 1973). 


\section{APPENDIX}

Example A.I

2-D BEAM

Two Story Frame

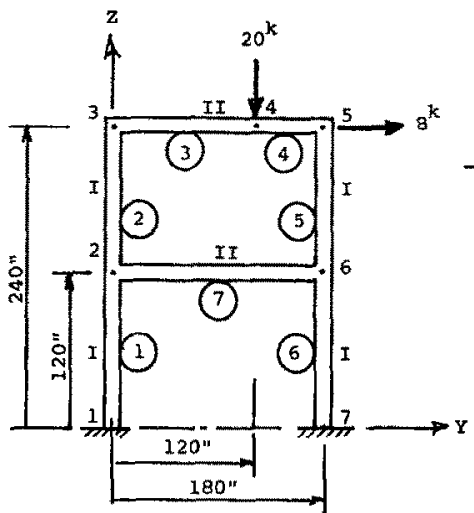

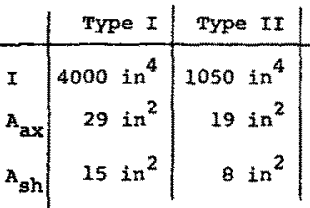

$E=30000 \mathrm{ksi}$

Poisson's Ratio $=0.3$

PRUN CENA:PREMSAP

AEXECUTION BEGINS

... ENTER PROBLEM TITLE (ONE LINE ONLY) TWO STORY FRAME

„. ENTER NUMBER OF JOINTS, NUMEER OF ELEMENT TYPES, AND ... NUMBER OF LOAD CASES (ON ONE LTNE SEPERATED BY COMAA)

$$
7,1,1
$$

...IS THE PROBLEM 2-DTMENSIONAL?

... ENTER Y FOR YES OR N FOR NO

...NOTE: POR 2-D PROBLEMS, ALL DATA MUST BE PREPARED IN Y $-Z$ PLANE

...ARE THERE BEAM, THLN SHELL UR PLATE ELEMENTS

$\ldots \underset{Y}{\ldots \text { INVOLVED IN THE PROBLEM? (ENTER } Y \text { OR } N \text { ) }}$

*** JOINT DATE

..FOR EACH JOINT ENTER FOLLOHING PER LINE

...BOUNDARY COND, CODE (O FOR FREE

...IN $Y-, Z-D T R, X_{-R O} .$, AND $Y-, z$-COORDINATES

$1:-1,1,1,0.0$.

$2:-0,0,0,0,120$

$3:-0,0,0,0,240$.

$4:-0,0,0,120,240$

$5:-0,0,0,120: 1240$.

$5:-0,0,0,180 ., 240$.
$5:-0,0,0,180.120$.

$7:-1,1,1,180 *, 0$.

*** ELEMENT DATA

-.. ENTER ELEMENT TYPE NUMBER

$\because$ ( $1=$ TRUSS, $2=$ BEAM, $3=$ PLANE STRESS MEMBRANE,

$\because \quad 4=A X I S Y M M E T R I C$ SOLID, PLANE STRAIN, PLANE STRESS,

$\because \quad 5=3 D$ SOLID 8-NODE-BRICK, $6=$ PLATE AND THIN SHELL,

$\because 27=$ BOUNDARY ELEMENT, $8=3$ D THICK SHELL 16-NODE-BRICK)

** BEAM ELEMENTS

... ENTER NUKBER OF ELEMENTS, WUMBER OE DIFF, GEOMETRY, .. AND NUMBER OF DTFE. MATERIALS

$7,2,1$

..FOR EACH DIFF, MATERTAL ENTER FOLLOWTNG PER LINE

-. MODULUS OF ELASTICETY AND POISSONS RATIO

i: $-30000,0.3$

...FOR EACH DIFF, GEOMETRY ENTER FOLLOWING PER LINE

-. AXIAL AREA, SHEAR AREA, MOMENT OF INERTIA

1:- $29 ., 15 ., 4000$

2:- 79, 8., 1050

-..FOR EACH ELEMENT ENTER FOLLOWTNG PER LINE

...JOINT NOS, I-(BEGINNING), J-(ENDING) $K$ -

$\cdots$ ( $K$ IS ANY POINT A DISTANCE AWAY FROM LINE I-J),

...AND I.D. NOS., OF MATERTAL AND GEOMETRY

1:- $1,2,6,1$,

$2:-2,3,4,1,1$

$3:-\quad 3,4,2,3,2$

$4:-4,5,6,1,2$

$=5,6,2,1,1$

$6:-6,7,1,1,1$

*. EnTER number of jotnts WTth concentrateo londs 
...FOR EACH LOADED JOINT ENTER FOLLOWING PER LINE

...JOINT NO. (IN INCREASING SEQ.), LOADS IN $Y_{-}, Z-D I R$, ,

ND MOMENT $X-X$

4, $\quad 0,,-20,0 ., 0$.

- . IS LISTING OF ABOVE DATA DESIRED?

...ENTER Y FOR YES OR N FOR NO

\#\$LIST -CDATA

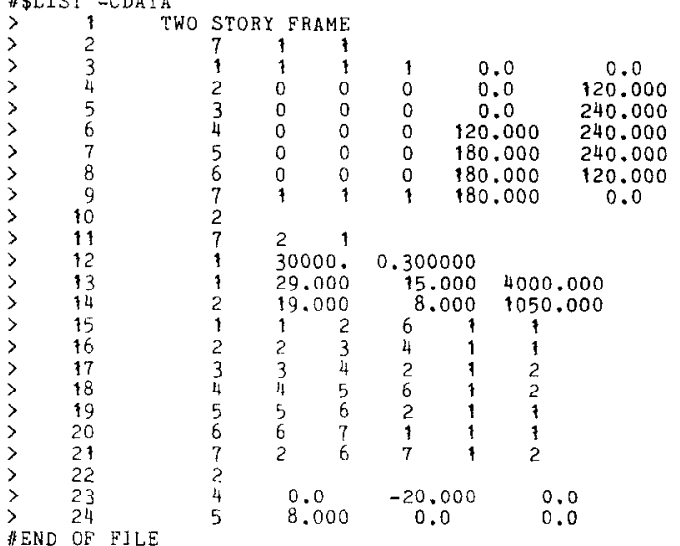

... IS ABOVE DATA CORRECT? (ENTER Y OR $\mathrm{N}$ )

.. THE PROGRAM IS FEADY TO STORE ABOVE DATA IN YOUR OWN FILE

...ACCORDING TO THE INPUT PORMAT OF MSAP

... ENTER YOUR OWN FILE NAME( 8 OR LESS CHARACTERS)

$$
\text { -STORY }
$$

... YOU ARE NOW READY TO OBTALN YOUR RESULTS BY TYPING

... \$RUN CENA:MSAP 5=-STORY - FOR STRUCTURAL ANALYSIS

... \$RUN CENA:MSAPLOT 5=-STORY - FOR GRAPHIC DISPLAY \#EXECUTION TERMINATED

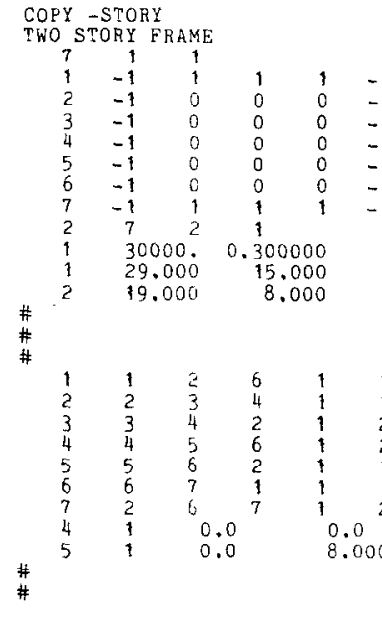

Example A.2

\section{Thick-walled cyinder}

$\mathbf{E}=30000 \mathrm{ksi}$

Poisson's Ratio $=0.3$

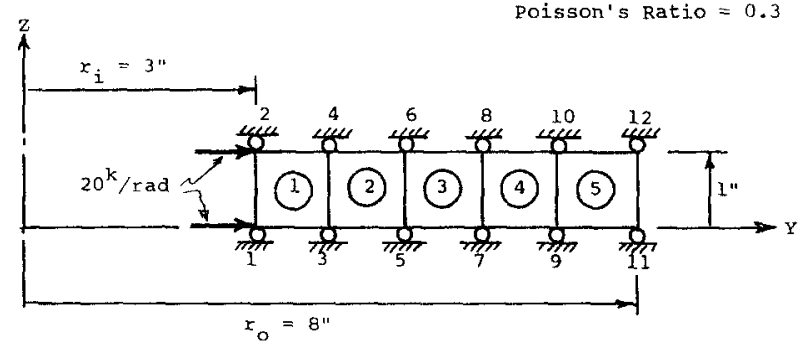

\#RUN CENA : PREMSAP

\#EXECUTION BEGINS

...ENTER PROBLEM TITLE (ONE LINE ONLY)
AXLSYMMETRIC CYLINDER 
$\ldots$ ENTER NUMEER OF JOINTS, NUMBER OF ELEMENT TYPES, AND

... WUHBER OF LOAD CASES (ON ONE LINE SEPERATED BY COMAR)

$12,1,1$

...IS THE PROBLEM 2-DIMENSIONAL?

...ENTER Y FOR YES OR N FOR NO

*+NOTE: FOR 2-D PROBLEMS, ALL DATA MUST BE PHEPARED IN Y-Z PLANE

...ARE THERE BEAM, THIN SHELL OR PLATE ELEMENTS

?... INVOLVED IN THE PROBLEM? (ENTER Y OR N)

*** JOINT DATA

$\ldots$ FOR EACH JOINT ENTER FOLLOWING PER LINE

- bOUNDARY COND. CODE (O FOR FREE, FOR CONSTRAINED)

...IN $Y$-DIR., IN $z$-DIR., AND THE $y-z$-COORDINATES

1:- $0,1,3,0$

3:- $0,1,3,1$

$4:-0,1,4,0$

$5:-0,1,5,0$

$6:-0,1,5,1$

$\therefore=0,1,0,0$

:

$9:-\infty, 1,7,0$

11:- $-0,1,8,0$

$12:-0,1,8,0$

** ELEHENT DATA

-...ENTER ELEMENT TYPE NIMMBER

$\because$ ( $1=$ TRUSS, 2=BEAM, 3=PLANE STRESS MEMBRANE

$\because \quad 4=A X I S Y M M E T R I C$ SOLID, PLANE STRAIN, PLANE STRESS

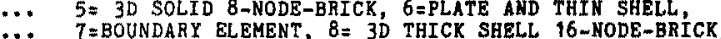
4

* 2-DIMENSTONAL FINITE ELEMENTS

...ENTER NUMBER OF ELEMENTS, AND NUMBER OF DIFF. MATERIALS

5,1

-.. ENTER ANALYSIS TYPE NUMEER

$\cdots(0=$ AXISYMMETRY, $1=$ PLANE STRAIH, 2 = PLANE STRESS)

. . FOR EACH DIFF. MATERIAL ENTER FOLLONTHG PER LIHE

$\cdots$ MODULUS OF ELASTICITY AND POISSONS RATIO
$1:-30000,0.3$

...FOR EACH ELEMENT ENTER FOLLOWING PER LINE

... NODES $I, J, K, L$ (FOR TRIANGULAR ELEM. $L=K$ ), MATERTAL $I . D$. NO. ...NSPRT (SEE NOTE), ELEMENT THICKNESS (FOR PLANE STRESS ONLY)

..NOTE: NSPRT

\#NSPRT $=0$ FOR STRESS OUTPUT AT ELEMENT CENTER

$\ldots \quad 1$ FOR NO STRESS OUTPUT

$\therefore \quad 8$ FOR STRESS AT CENTER \& MIDPOTNT OF SIDE I-J

$\therefore \quad 20$ FOR STRESS AT CENTER MIDPOINT OF ALL SIDES

$1:-\quad 1,3,4,2,1,20$

2:- $\quad 3,5,6,4,1,20$

3:- $\quad 5,7,8,6,1,20$

5:- $\quad 9,11,12,10,1,20$

- . ENTER NUMEER OF JOTNTS WITH CONCENTRATED LOADS

- FOR EACR LOADED JOINT ENTER FOLLOWING PBR LIHE

...JOINT NO. (IN INCBFASTNG SEQ.), AND LOADS IN Y-, Z-DIR.

20,0

...IS LISTING OF ABOVE DATA DESIRED?

...ENTER Y FOR YES OR N FOR NO

...THE PROGRAM IS READY TO STORE ABOVE DATA IH YOUR OWN FILE

$\because$.. ACCORDING TO THE INPUT FORMA? OF MSAP

. ENTER youn OWN FILE NaME ( 8 OR LESS characters)

-AXISYMM

... YOU ARE NOW READY TO OBTAIN YOUR RESULTS BY TYPING

-.+ DRUN CENA:MSAP 5=-AXISYMM - FOR STRUCTURAL ANALYSIS

-.. SRUN CEKAiMSAPLOT $5=-A X I S Y M M$ - FOR GRAPHIC DISPLAY

-EXECUTION TERMINATED

\$COPY -AXTSYMM

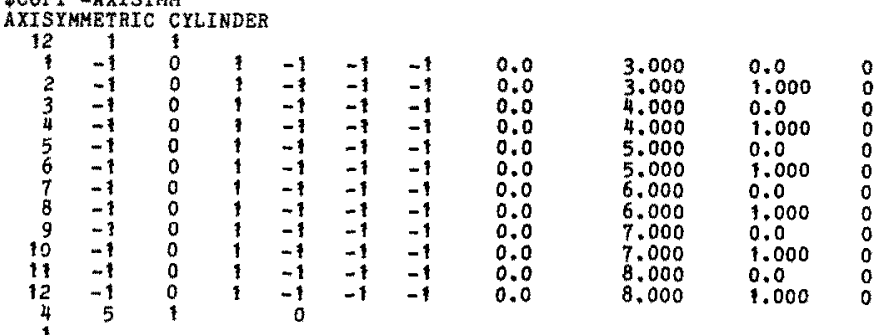




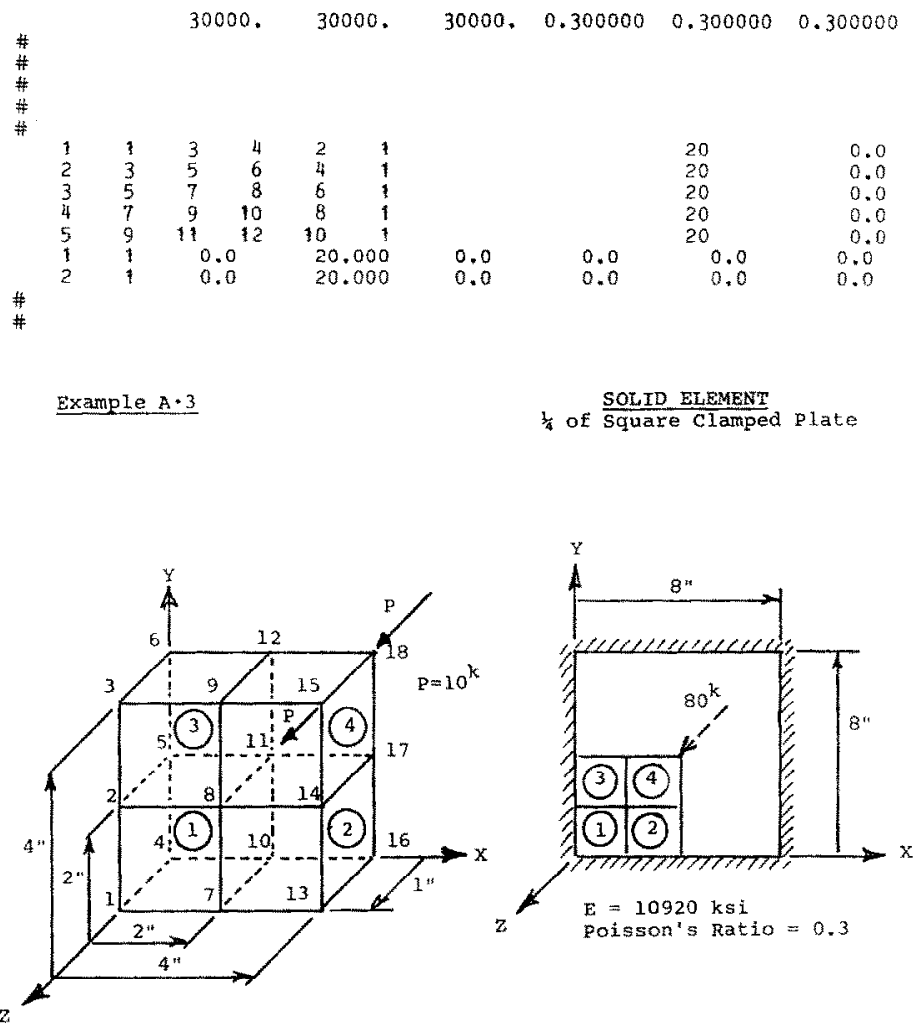

ARUN CEWA : RREMSAP \#EXECUTION BEGINS

\#. FNTER PROBLEM TITLE (ONE LINE ONLY)

SOLID ELEMENT - 1/4 OF SQ. CENTRALLY LOADED CLAMPED PLATE

...ENTER NUMBER OF JOINTS, NUMBER OF ELEMENT TYPES, AND

... NUMBER OF LOAD CASES (ON ONE LINE SEPERATED BY COMMA) $18,1,1$

...IS THE PROBLEM 2-DIMENSIONAL?

... ENTER Y FOR YES OR N FOR NO

$$
\text { N }
$$

ARE THEPE BEAM THIN SHELL OR PLATE ELEMENTS

. ARE THERE BEAM, HAR SHELL (ENTER Y OR N)

$$
\text { IN }
$$

* * JOINT Data

... FOR EACH JOTHT ENTER FOLLOWING PER LINE

... BOUNDARY COND. CODE (O FOR FREE, I FOR CONSTRAINED)

.. IN $X-, Y-, Z-D I R ;$, AND $X-, Y-, Z$ Z-COOPDINATES

$1:-1,1,1,0,0,1$

$2:-1,1,1,0,2$,

$3:-1,1,1,0,4$,

$4:-1,1,1,0,0,0$

$5:-1,1,1,0,2,0$

$6:-1,1,1,0,4,0$

$7:-1,1,1,2,0$

$0:-0,0,0,2,2$,

n:- $1,1,1,2,0$

$1:-0,0,0,2,2,0$

$2:-0,1,0,2,4,0$

$1,0,0,4,1$

$6:-1,1,4,0,0$

$17:-1,0,0,4,2,0$

$8:-\quad 1,1,0,4,4,0$

*** ELEMENT DATA

... ENTER ELEMENT TYPE NUMBER

$\therefore$ ( $1=$ TRUSS $, 2=B E A M, \quad 3=P L A N E$ STRESS MEMBRANE

$\cdots \quad 4=A X I S Y M M E T R I C$
$\cdots$

$\cdots \quad 5=30$ SOLID 8-NODE-BIICK, 6 = FLATE AND THIN SHELL,
$\because \quad 7=B O U N D A R Y$ ELEMENT, $8=3$ THICK SHELL $16-N O D E-B R I C K)$

** 3-D SOLID ELEMENTS

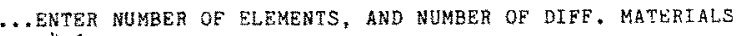
4,1

...FOR EACLI DIFF, MATERIAL ENTER FOLLOWING PER LINE 
-. MODULUS OR ELASTICTTY, AND POLSSONS RATIO

$1:-10920,0.3$

. FOR EACH ELEHENT ENTER FOLLOWTNO PER LINE

-..NODE WOS. (CORAESPONDING TO ELEM, NODES $(1,2,3,4,5,6,7,8$ ),

.. INTERGRATION ORDER (2 FOR RECTANGULAR ELEM., OR 3 FOR SKEVED ELEM.),

...MATERIAL I.D. NO*, AND TWO FACE NUMBERS

*.* (FOR STRESS output FROM Followino nas. $0,1,2,3,4,5$, on 6 )

$1 \div-10,11,5,4,7,8,2,1,2,1,6,0$

$2:-16,17,11,10,13,14,8,7,2,7,6,0$

$3 \div-11,12,6,5,8,9,3,2,2,1,6,0$

$4:-17,18,12,11,14,15,9,8,2,7,6,0$

*..ENTER NDMBER OF JOINTS WTTH CONCENTRATED LOADS

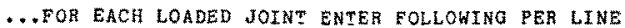

...JOINT NO. (IN INCREASING SEQ.), AND LOADS IN $X-Y, Y-2-D I R$.

$15,0,0,10$

\#. IS LISTING OF ABOVE DATA DESLREU?

+..ENTER $\square$ FOR YES OR N FOR NO

..THE PROGRAN IS READY TO STORE AEOVE DATA IN YOUR OWN ETLE

... ACCORDTNG TO THE IMPUT FORMAT OF MSAP

...ENTER YOUH OWN FLLE NAME( 8 OR LESS CHARACTERS) -SOLID

.. YOU ARE NOW FEADY TO OBTAIN YOUR RESULTS BY TYPING

-. \$EUN CENA:MSAP $5=-5 O L I D$ - FOR STRUCTURAL ANALYSTS

F.. \$RUN CENA:MSAPLOT 5=-SOLID - FOR GRAPHIC DISPLAY

EXECUTION TERMIHATED

$\$ C O P Y$-SOLTD

SOLTD ELEMEN? - 1/4 OF SQ. CENTRALLY LOADED CLAMPED PLATE

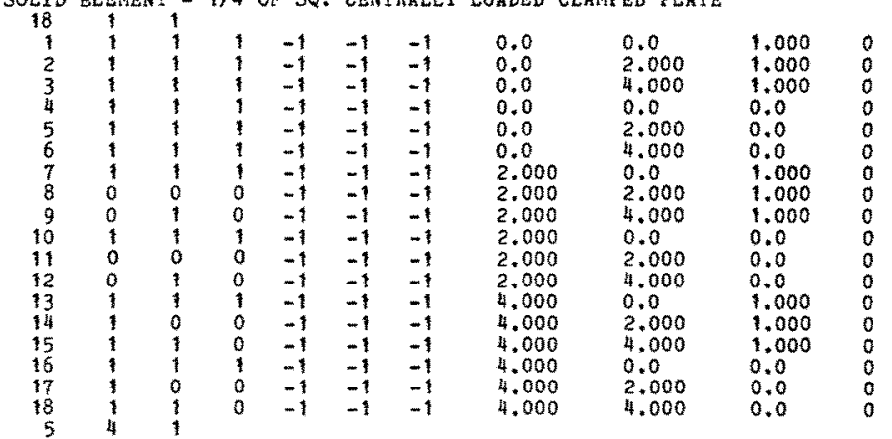

$\#$
$\#$
$\#$
$\#$
$\#$
$\#$
$\#$
$\#$

10920.300000

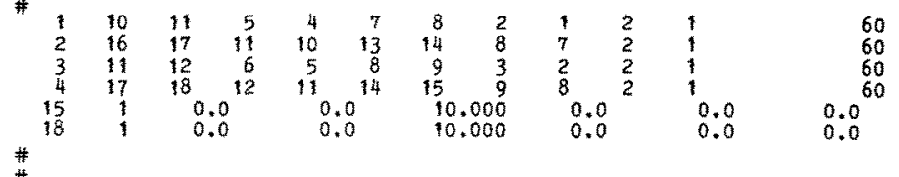

Example A.4

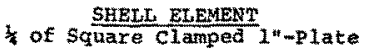

$t=10920 k s i$

Poisson's Ratio $=0.3$
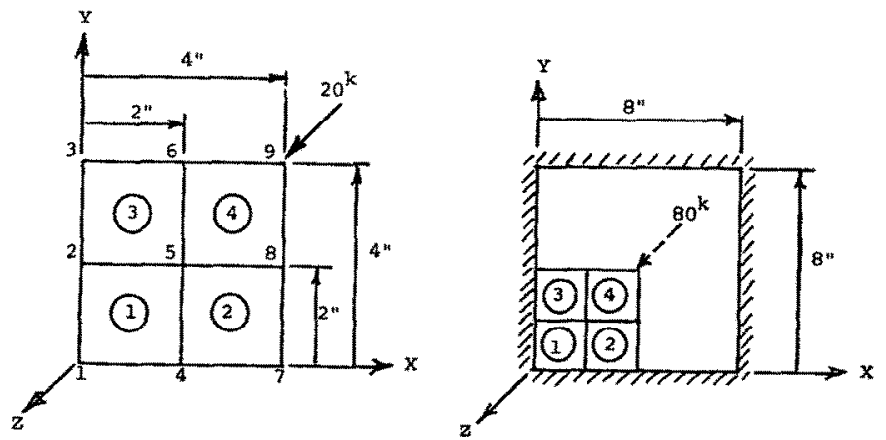
- EVTER PHOBLEM TTTLE (ONE LINE ONLY)

SHELL ELEMEN? - IA OF SO. CENTRALIY LOADED CLAMPEO PLATE

. . ENTER NUEBER OF JOINTS, NUMBER OF ELENENT TYPES, AND

... Number of LOAD cases (ÓN ONE LINE SEPERATEd By COMMa) $9,1,1$

... IS THE PROBLEH 2-DIMENSIONAL?

.. Enter y fOR yes or n for no

$\mathrm{N}$

- AARE THERE BEAM, THIN SHELL OR PLATE BLEKENTS

... INVOLVED IN THE PROBLEM? (ENTER Y OR N)

*** JOInT DATA

\#FOR EACH JOTHT ENTER FOLLOWING PER LINE

..BOUNDARY COND. CODE (O FOR FREE, I FOR CONSTBAINED)

$\cdots$ IN $X-, Y-, Z-D H_{*}, X_{-}, Y-, Z-R O^{*}$, , AND $X-, Y-, Z-C O O R D$.

$1:-1,1,1,1,1,1, n$,

$2:-1,1,1,1,1,1,0,2$

$3:-1,1,1,1,1,1,0,4$

$4:-1,1,1,1,7,1,2,0$

$5:-0,0,0,0,0,1,2,2$

$6:-0,1,0,7,0,1,2,4$

$7:-1,1,7,1,3,1,4,0$

$8:-1,0,0,0,1,1,4,2$

** ET EMENT DAT

…ENTER ELEMENT TYPE NUMBER

$\therefore$ (1=TRUSS, $2=$ BEAM, 3=PLANE STRESS MEMBRANE

$\because \quad$ H=AXISYMMETRIC SOLID, PLANE STRAIN, PLANE SERESS,

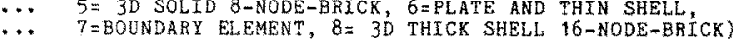

** PLATE OR THIN SHELL ELEMENTS

...ENTEFNUMBER OF ELEMENTS, AND NUMBER OE DIEE, MATERIALS 4,1

-..FOR EACH DIFF. MATERTAL FNTER FOL.1.OWING PER I,TNF

- MODULUS OF ELASTICETY AND POISSONS RATIO

i: $-10920,0.3$

.. FOR EACH ELENENT ENTER FOLLOHING PER LINE

... NODES $I, J, K, L(F O R$ TRIANGULAR ELEM. $L=0$ ), MATERIAL I.D. NO., -..AND ELEMENT THICKNESS

$1:-1,4,5,2,1,1$

$2:-4,7,8,5,1,1$

$3:-2,5,6,3,1,1$

$4:-5,8,9,6,1,1$

-.. EUTER MUMBER OF JOIN"S WTH CONCENTRATED LOADS

FOR EACH LOADED JOTNT ENTER FOLLOWYWG PER LINE

$\ldots$ JOIN? WO. (IN INCREASING SEQ.), LOADS IN $X-, Y-, Z$-DIR.

$\because$ AND MOMENSS ABOUT $X-X, Y \rightarrow Z, Z-Z$

$9,0,0,20$

... LS LISTING OF ABOVE DATA DESTRED?

... ENTER y FOR yes OR n FOR NO

N

.. THE PROGRAM IS READY TO STORE ABOVE DATA IN YOUR OWN FILE

. ACCORDING TO THE INPUT FORMAT OF MSAP

- . ENTER YOUR OWN EILE NAME(B OR LESS ChARACTERS)

-SHELL

.. YOU ARE NOW READY TO OBTAIA YOUR RESULTS BY TYPING

..\$RUN CENA:MSAP 5=-SHELL - FOR STRUCTURAL ANALYSIS

... \$RUN CENA:MSAPLOT 5=-SHELL - EOR GRAPHIC DISPLAY

EXECUTION TEFMIUATED

\$COPY -SHELL

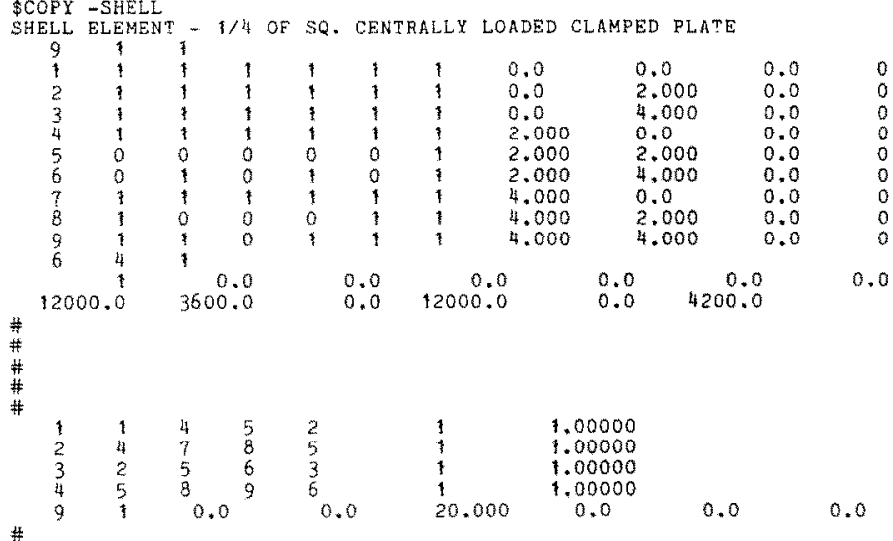

